\title{
Improved Anticancer Effects on Various Cancers with Combinations of Chemotherapeutic Drugs or Vitamin C and D-Fraction
}

\author{
Sensuke Konno*, Bobby Alexander, Drew Freilich, Muhammad Choudhury \\ Department of Urology, New York Medical College, Valhalla, USA. \\ Email: *sensuke_konno@nymc.edu \\ Received April $9^{\text {th }}, 2013$; revised May $10^{\text {th }}, 2013$; accepted May $18^{\text {th }}, 2013$ \\ Copyright (C) 2013 Sensuke Konno et al. This is an open access article distributed under the Creative Commons Attribution License, \\ which permits unrestricted use, distribution, and reproduction in any medium, provided the original work is properly cited.
}

\begin{abstract}
Although chemotherapy is one of several therapeutic options for cancer patients, the outcomes have been less satisfactory with palpable side effects in many cases. To help improve the efficacy of chemotherapy, we examined whether D-fraction (DF), a bioactive mushroom extract, would potentiate anticancer effects of those drugs in vitro. Seven types of cancer cell lines, including breast, lung, stomach, colon, prostate, bladder, and kidney cancers, were tested with various chemotherapeutic drugs and their combinations with DF. Compared to individual drugs alone, combinations of those drugs and DF have indeed improved anticancer activity, resulting in the significant $(p<0.05)$ cell viability reduction in all cancer cells. As vitamin C (VC) has been insinuated to potentiate bioactivity of DF, combination of DF (300 $\mu \mathrm{g} / \mathrm{ml})$ and $\mathrm{VC}(200 \mu \mathrm{M})$ was also examined. Such studies showed that $\mathrm{DF} / \mathrm{VC}$ combination led to the drastic $(\geq 90 \%)$ viability reductions in 6 cancer cells and the 70\% reduction in 1 cancer cell type. These results were superior to those from combinations of drugs and DF. To assess if such a profound cell viability reduction by DF/VC combination might be attributed to apoptosis, this possibility was tested by Western blots. Analyses revealed that anti-apoptotic bcl-2 was down-regulated while pro-apoptotic Bax was up-regulated with DF/VC combination, indicating induction of apoptosis. It is plausible that $\mathrm{DF} / \mathrm{VC}$ combination may induce apoptosis, resulting in the severe cell viability reduction. Therefore, DF may have a great potential as an adjuvant agent that can be combined with chemotherapeutic drugs or with VC for the improved treatment of various human malignancies.
\end{abstract}

Keywords: D-Fraction; Vitamin C; Chemotherapy; Apoptosis; Human Cancers; Maitake

\section{Introduction}

The World Health Organization (WHO) estimates that 7.6 million deaths worldwide would come from cancers, which remain a global health problem [1]. Cancer is indeed a leading cause of death worldwide with five major cancer types from lung, stomach, liver, colon, and breast [1]. Several conventional therapeutic options, such as surgery, internal/external radiotherapy, hormone therapy, chemotherapy, immunotherapy etc., are currently available. Although they may have the initial good response rates, most deaths are attributed to a subsequent relapse or recurrence of the disease developed in large numbers of patients [2]. For instance, after complete resection of kidney tumor (by nephrectomy), $20 \%-30 \%$ of patients would progress to a metastatic disease with the 5-year

\footnotetext{
${ }^{*}$ Corresponding author.
}

survival rate of $<10 \%$ [3], which is devastating and dismal. Nevertheless, chemotherapy is yet currently one of the most common therapeutic options, although the outcomes have been rather disappointing or unsatisfactory with severe side effects [4]. However, we cannot completely rule out the possibility that chemotherapy could be altered in such a way that its efficacy is improved while the needed dosages to gain results are decreased.

To improve the efficacy or anticancer property of chemotherapy, we have been exploring combination therapy using chemotherapeutic drugs and natural agents extracted from herbs, plants, mushrooms, seeds, fruits etc. Among those agents, we were particularly interested in "D-fraction (DF)", a bioactive extract from maitake mushroom (Grifola frondosa). DF is the protein-bound polysaccharide or proteoglucan, consisting of a bioactive component known as $\beta$-glucan [5]. It has been commer- 
cially available for a variety of medical and scientific research, and a number of studies have shown its immunomodulatory and antitumor activities in an animal model [6,7]. For instance, antitumor activity of DF has been shown in tumor-bearing mice through activation of various immune effectors such as macrophages, cytotoxic T-lymphocytes, natural killer cells etc. [6,7]. Additionally, antiviral effect of DF was demonstrated on hepatitis B [8] and also confirmed on human immunodeficiency virus (HIV)/AIDS in anti-HIV drug screening tests conducted by the US National Cancer Institute in 1992 [9]. Thus, DF appears to be an interesting and promising natural agent that deserves further studies on its antitumor activity. Moreover, the US Food and Drug Administration (FDA) has exempted DF from a phase I study of toxicology. The FDA has also approved DF for the Investigational New Drug (IND) application for a phase II pilot study on patients with advanced breast and prostate cancer [10]. It has been reported that a randomized clinical trial of DF on healthy subjects (non-cancerous participants) confirmed no palpable ailments or adverse effects on any participants [11]. Therefore, all these facts support the safety of DF on cancer patients as well as normal healthy people.

Accordingly, we investigated if anticancer effects of various chemotherapeutic drugs might be potentiated in combination with DF in seven different types of human cancer cells. Those included breast, lung, stomach, colon, prostate, bladder, and kidney cancers. As it has been proposed that vitamin $\mathrm{C}(\mathrm{VC})$ could modulate the bioactivity of DF [12], we also examined if such combination might have any (anticancer) effects on those various cancer cells. More details and notable findings are described herein.

\section{Materials and Methods}

\subsection{Cell Culture}

A total of seven human cancer cell lines were obtained from the American Type Culture Collection (ATCC; Manassas, VA) and employed in this study: breast cancer MDA-MB231 cells, lung cancer A549 cells, stomach cancer AGS cells, colon cancer Caco-2 cells, prostate cancer PC-3 cells, bladder cancer T24 cells, and kidney cancer ACHN cells. They were maintained in RPMI 1640 medium containing $10 \%$ fetal bovine serum, penicillin $(100$ units $/ \mathrm{ml})$, and streptomycin $(100 \mu \mathrm{g} / \mathrm{ml})$ at $37^{\circ} \mathrm{C}$ in a humidified incubator. Chemotherapeutic drugs were purchased from Sigma-Aldrich (St. Louis, MO) and standardized D-fraction (DF) was a gift from the manufacturer (Mushroom Wisdom, Inc., East Rutherford, NJ). For experiments, certain chemotherapeutic drugs being clinically used were tested in specific cancer cells as fol- lows: paclitaxel (PTX) was tested in breast (MDAMB231) and prostate (PC-3) cancers; cisplatin (CPL) was in lung (A549) and bladder (T24) cancers; and 5-fluorouracil (5-FU) in stomach (AGS), colon (Caco-2), and kidney (ACHN) cancers. These different cancer cells were seeded at the initial cell density of 1 or $2 \times 10^{5}$ cells $/ \mathrm{ml}$ in 6-well plates or T-75 flasks and treated with varying concentrations of specific drugs assigned as well as combinations of those drugs and DF. Additionally, these cancer cells were separately treated with combination of DF and vitamin C (VC). The effects of chemotherapeutic drugs alone, their combinations with DF, or $\mathrm{DF} / \mathrm{VC}$ combination were then assessed on cell viability by MTT assay. All experiments have been separately performed three times and statistical analysis was also performed accordingly.

\subsection{MTT Assay}

Cell viability was determined by MTT (3-[4,5-dimethylthiazol-2-yl]-2,5-diphenyl-tetrazolium bromide) assay following the vendor's protocol (Sigma-Aldrich, St. Louis, MO) with minor modifications. This MTT system is based on the conversion of the water-soluble MTT to an insoluble purple formazan through mitochondrial dehydrogenases in viable cells. Briefly, at the harvest time, MTT reagent $(0.5 \mathrm{mg} / \mathrm{ml})$ was added to all wells in the 6-well plate, which was then incubated for $3 \mathrm{~h}$. After MTT reagent was removed from all wells, DMSO (dimethyl sulfoxide) was added to each well to dissolve the formazan crystals (with purple color). Absorbance of fomazan solution was read in a microplate reader, and cell viability was expressed by the $\%$ relative to the control reading $(100 \%)$.

\subsection{Western Blot Analysis}

The procedures essentially followed the protocol described previously [13]. Briefly, cell lysates were obtained from control and agent-treated cells by "freeze thaw" in liquid nitrogen. An equal amount of cell lysates $(7 \mu \mathrm{g})$ was subjected to $10 \%$ SDS-polyacrylamide gel electrophoresis and transferred to a nitrocellulose membrane. The blot (membrane) was incubated for $90 \mathrm{~min}$ with the primary antibodies against bcl-2 or Bax (Santa Cruz Biotechnology, Santa Cruz, CA), followed by 30-min incubation with the secondary antibody conjugates. The specific immunoreactive protein bands were then detected by chemiluminescence following the manufacturer's protocol (Kirkegaard and Perry Laboratories, Gaithersberg, MD).

\subsection{Statistical Analysis}

All data were presented as mean $\pm \mathrm{SD}$ (standard devia- 
tion), and statistical differences between groups were assessed with either one-way analysis of variance (ANOVA) or the unpaired student's $t$ test. Values of $p<0.05$ were considered to indicate statistical significance.

\section{Results}

\subsection{Effects of Chemotherapeutic Drugs Alone or Their Combinations with DF on Cell Viability of Various Cancer Cells}

Seven different cancer cells were treated with varying concentrations of specific chemotherapeutic drugs as follows: MDA-MB231 and PC-3 cells were treated with PTX (0 - $30 \mathrm{nM})$; A549 and T24 cells were with CPL (0 - $100 \mu \mathrm{M})$; and AGS, Caco-2, and ACHN with 5-FU (0 $300 \mathrm{ng} / \mathrm{ml}$ ). In addition, these cancer cells were also treated with combinations of drugs and DF $(300 \mu \mathrm{g} / \mathrm{ml})$ as follows: both MDA-MB231 and PC-3 cells were treated with combinations of PTX and DF; A549 and T24 cells with combinations of CPL and DF; and AGS, Caco-2, and ACHN cells with combinations of 5-FU and DF. After $72 \mathrm{~h}$, all cells were analyzed for cell viability by MTT assay. It should be noted that DF $(300 \mu \mathrm{g} / \mathrm{ml})$ by itself had little effects on all seven cancer cells in our pilot study (data not shown). Moreover, the concentrations of these drugs used were the estimated maximum physiologically tolerable levels.

For the effects on MDA-MB231 cells, MTT assay showed that PTX by itself had the potent effect on MDA-MB-231 cells, resulting in a $38 \%, 47 \%$, and $68 \%$ reduction in cell viability at 6,10 , and $30 \mathrm{nM}$, respectively. However, its combination with DF $(300 \mu \mathrm{g} / \mathrm{ml})$ slightly improved such an efficacy (i.e. only $<10 \%$ increase in the viability reduction) (Figure 1(a)).

For A549 cells, no significant reduction in cell viability of A549 cells was observed with CPL concentrations up to $100 \mu \mathrm{M}$ with a $28 \%$ viability reduction. Its combination with DF $(300 \mu \mathrm{g} / \mathrm{ml})$ had the slightly improved effects on the cell viability reduction (up to only $32 \%$ ) (Figure 1(b)).

For AGS cells, 5-FU seemed to have only a little effect on AGS cells and its highest concentration of $300 \mathrm{ng} / \mathrm{ml}$ tested led to a $22 \%$ viability reduction. However, its combination with DF $(300 \mu \mathrm{g} / \mathrm{ml})$ became highly potent or more effective, resulting in a $25 \%$ and $40 \%$ viability reduction from a $13 \%$ and $22 \%$ reduction with 5 -FU (200 and $300 \mathrm{ng} / \mathrm{ml}$ ) alone, respectively (Figure 1(c)).

For Caco-2 cells, no significant effect with 5 -FU was seen up to $300 \mathrm{ng} / \mathrm{ml}$ with a $31 \%$ viability reduction in Caco- 2 cells. Yet, its combination with DF $(300 \mu \mathrm{g} / \mathrm{ml})$ led to the improved viability reduction: even 5-FU (100 $\mathrm{ng} / \mathrm{ml}$ ) with no apparent effect showed a $35 \%$ viability reduction with DF, and combinations of 200 and 300 $\mathrm{ng} / \mathrm{ml}$ of 5 -FU (with a $13 \%$ and $31 \%$ viability reduction, respectively) and DF resulted in a 50\% and $62 \%$ viability reduction, respectively (Figure 1(d)).

For PC-3, T24, and ACHN cells, a significant (25\%) viability reduction was only seen in PC-3 cells with 30 nM PTX (Figure 1(e)), but no such a reduction was seen in T24 and ACHN cells with given drugs (Figures 1(f) and $\mathbf{1}(\mathrm{g}))$. Nevertheless, combinations of PTX, CPL, or $5 \mathrm{FU}$ and $\mathrm{DF}(300 \mu \mathrm{g} / \mathrm{ml})$ led to a maximum $45 \%, 42 \%$, and $49 \%$ viability reduction in PC-3, T24, and ACHN cells, respectively (Figures 1(e)-(g)).

Taken together, these results suggest that DF appears to enhance anticancer activity of chemotherapeutic drugs to some extent on a variety of cancer cell types.

\subsection{Synergistic Effects of Combination of DF and VC on Cell Viability}

While VC has been implied to enhance bioactivity of DF [12], it has also been long known as the beneficial nutritional supplement and has been extensively studied for a potential role in cancer prevention and treatment $[14,15]$. We then examined if combination of DF and VC could exhibit any anticancer or inhibitory activity against these cancer cells. All seven cancer cells were cultured with combination of DF $(300 \mu \mathrm{g} / \mathrm{ml})$ and VC $(200 \mu \mathrm{M})$ and cell viability was assessed at $24 \mathrm{~h}$. It should be noted again that neither DF $(300 \mu \mathrm{g} / \mathrm{ml})$ nor VC $(200 \mu \mathrm{M})$ alone had any effects on these cancer cells (data not shown). The results were then summarized in Table 1.

Overall, combination of $\mathrm{DF}$ and $\mathrm{VC}$ was highly potent or cytotoxic, inducing a $\geq 90 \%$ viability reduction in nearly all cancer cells except for a $\sim 70 \%$ viability reduction in lung cancer A549 cells (Table 1). These findings also indicate that DF and VC may work synergistically to induce such a profound cell viability reduction. Therefore, DF/VC combination appears to affect those cancer cells more severely than any combinations of chemotherapeutic drugs and DF (Figures 1(a)-(g)).

\subsection{Possible Induction of Apoptosis by DF/VC Combination}

To obtain a better understanding of such a profound viability reduction induced by $\mathrm{DF} / \mathrm{VC}$ combination, whether it would be linked to apoptosis (programmed cell death) was examined. Seven cancer cells were exposed to combination of DF $(300 \mu \mathrm{g} / \mathrm{ml})$ and $\mathrm{VC}(200$ $\mu \mathrm{M})$ for $24 \mathrm{~h}$ and subjected to Western blot analysis on two key apoptosis regulators, bcl-2 and Bax. The results revealed that bcl-2 expression was down-regulated while Bax expression was up-regulated with DF/VC combination in all seven cancer cells (Figure 2). As bcl-2 is known as an anti-apoptotic regulator while Bax is a pro- 
(a) MDA-MB231 Cells

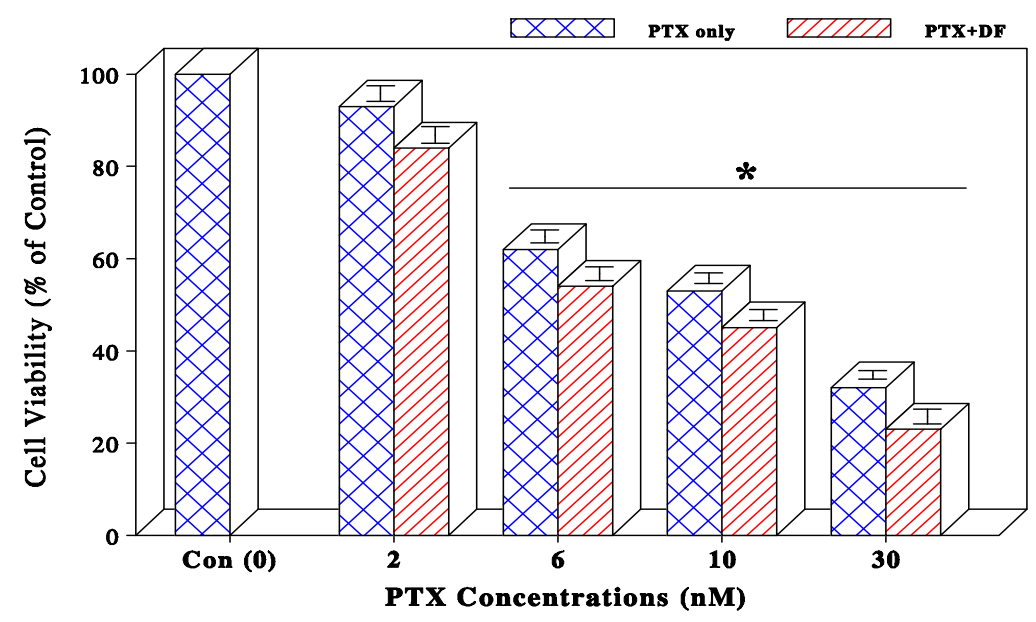

(b) A549 Cells

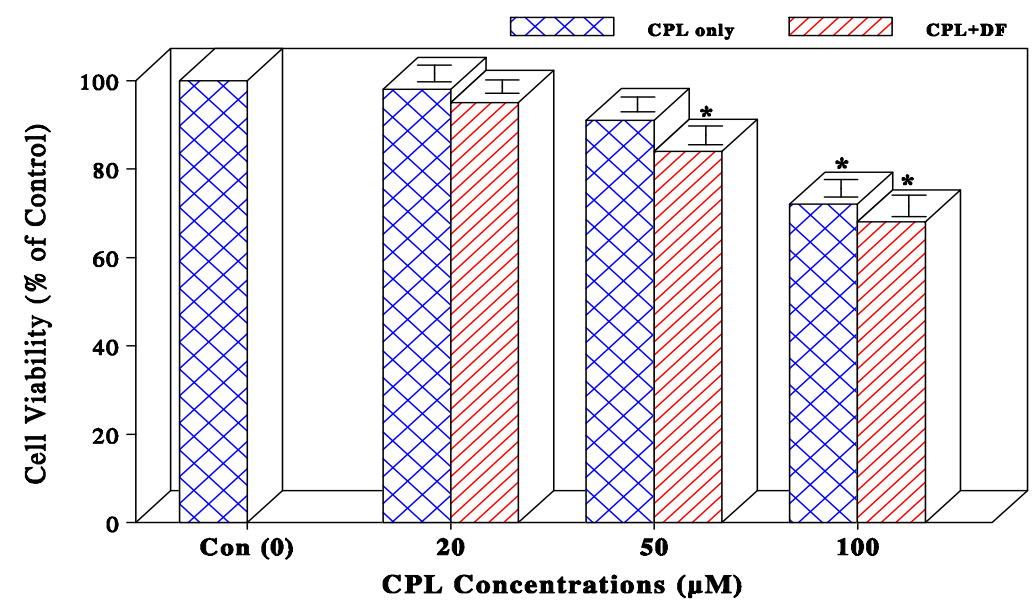

(c) AGS Cells

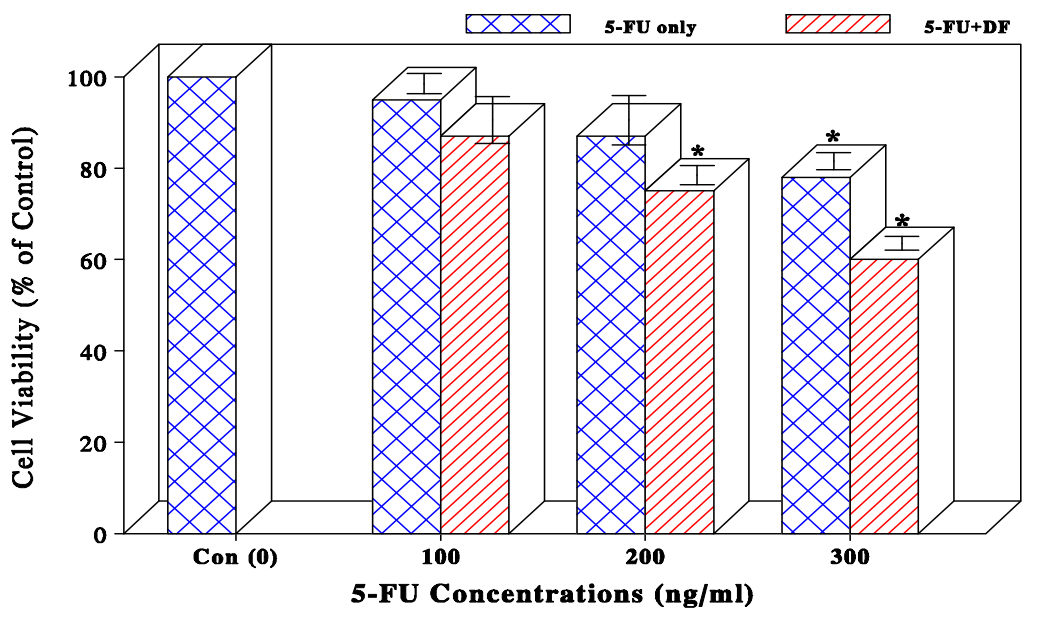



or Vitamin C and D-Fraction

(d) Caco-2 Cells

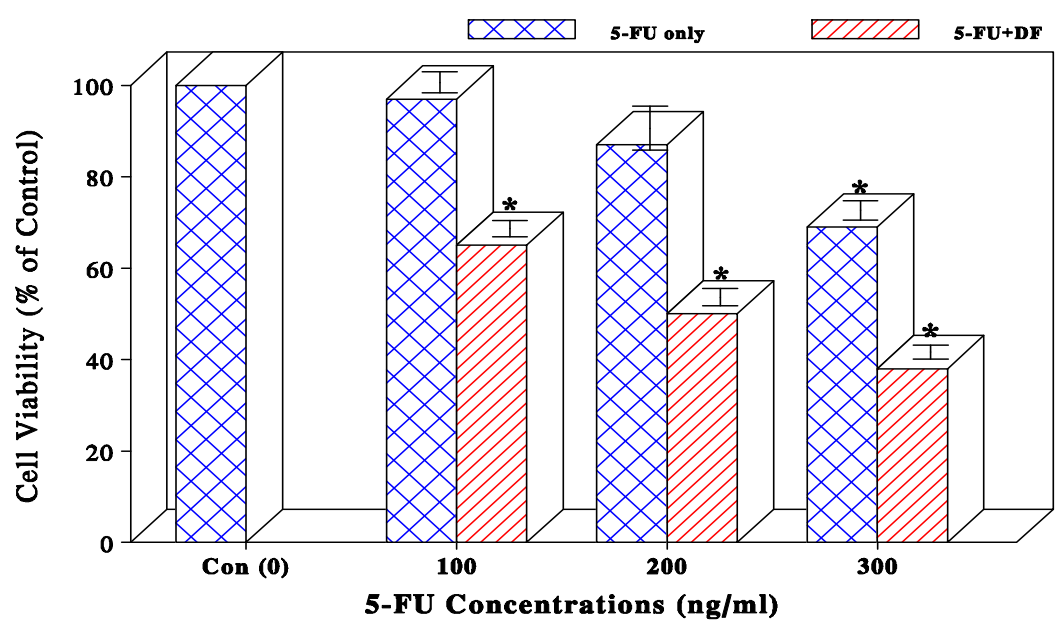

(e) PC-3 Cells

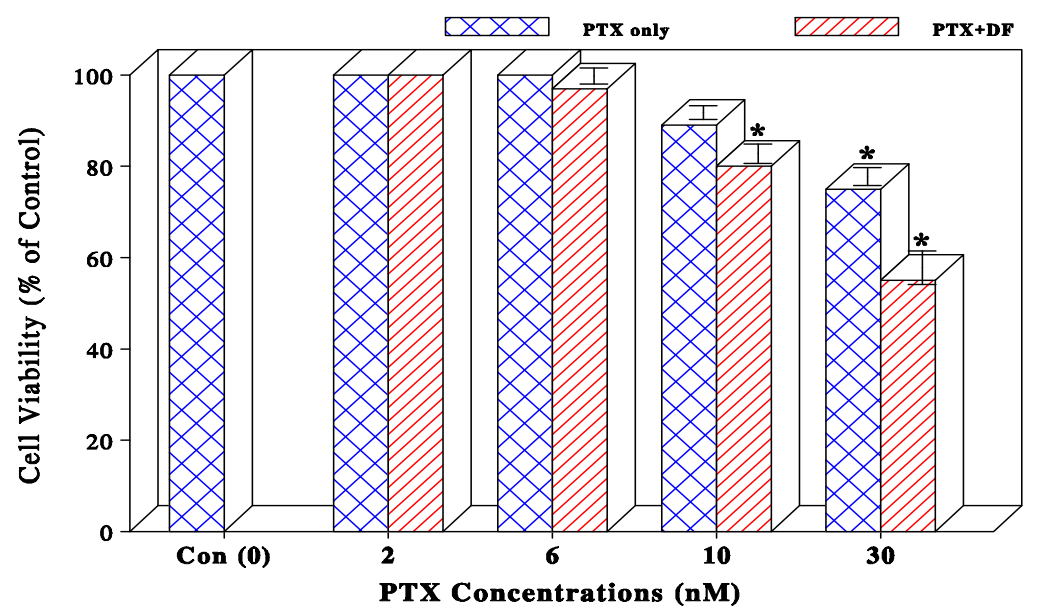

(f) T24 Cells

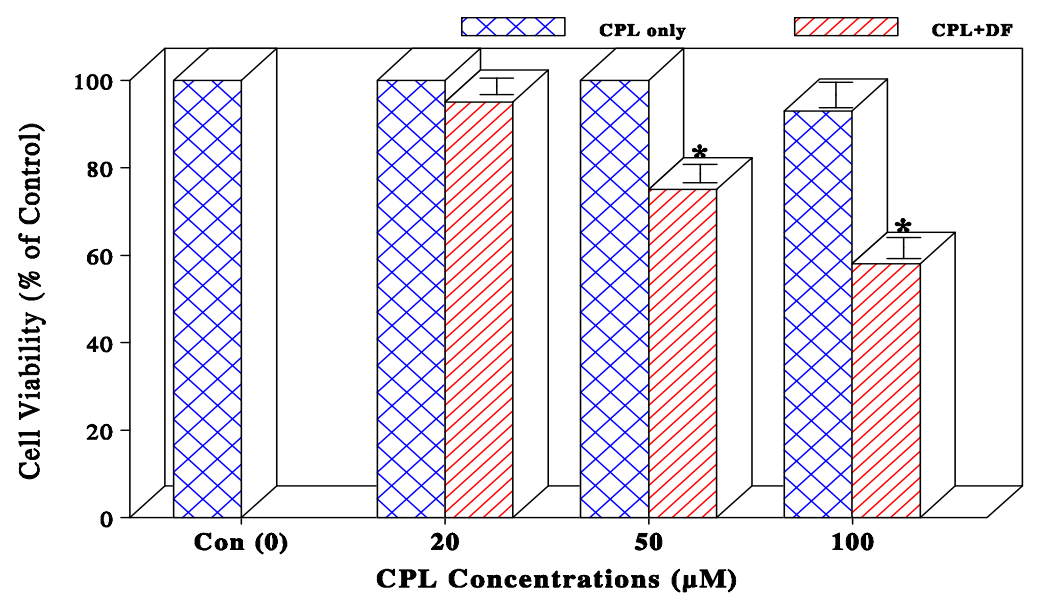




\section{(g) ACHN Cells}

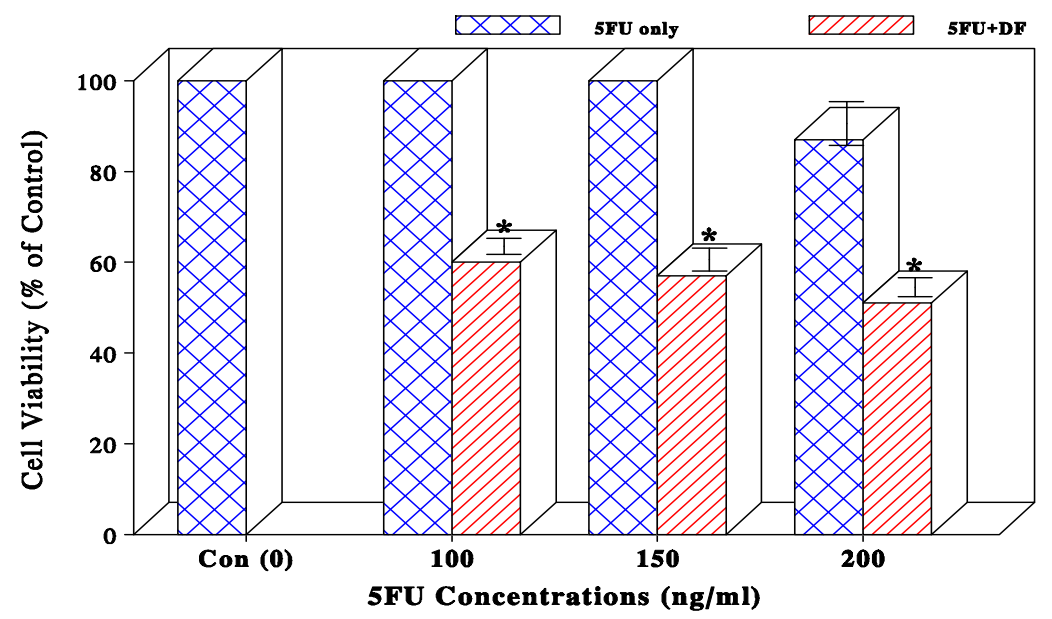

Figure 1. MDA-MB231 (a) and A549 (b) cells were treated with PTX (0 - 30 nM) and CPL (0 - 100 $\mu$ M), respectively. At 72 h, all cells were subjected to MTT assay to assess cell viability, which was expressed by the percent (\%) of viable cells relative to controls (100\%). The data are mean \pm SD (standard deviation) from three separate experiments; AGS (c) and Caco-2 (d) cells were separately treated with $5-\mathrm{FU}(0-300 \mathrm{ng} / \mathrm{ml})$ for $72 \mathrm{~h}$ and subjected to MTT assay. Cell viability was expressed by the \% of viable cells relative to controls $(\mathbf{1 0 0 \% )}$. The data are mean \pm SD from three separate experiments; PC-3 (e), T24 (f), and ACHN (g) cells were treated with PTX (0 - $30 \mathrm{nM})$, CPL (0 - $100 \mu \mathrm{M})$, and 5-FU (0 - $300 \mathrm{ng} / \mathrm{ml})$, respectively. Cell viability at $72 \mathrm{~h}$ was assessed by MTT assay and expressed by the \% of viable cells relative to controls (100\%). The data are mean \pm SD from three independent experiments $\left({ }^{*} p<0.05\right.$ compared with respective controls).

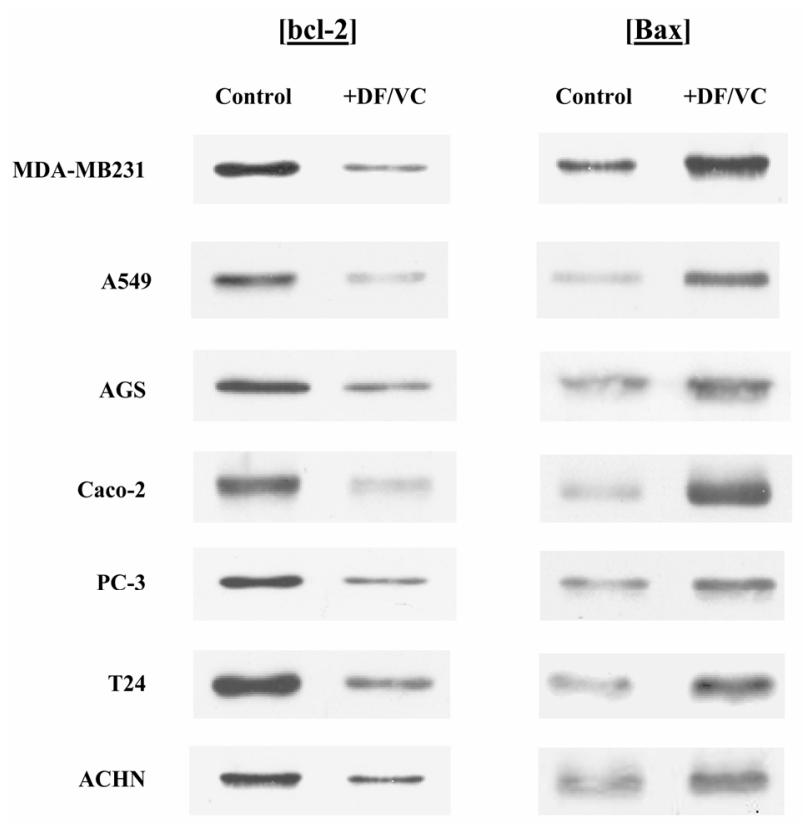

Figure 2. Effects of DF/VC combination on bcl-2 and Bax. After seven cancer cells were treated with combination of DF $(300 \mu \mathrm{g} / \mathrm{ml})$ and VC $(200 \mu \mathrm{M})$ for $24 \mathrm{~h}$, expressions of bcl-2 and Bax in each cell line treated with or without DF/VC were analyzed on Western blots. Autoradiographs show that bcl-2 expression was down-regulated (diminished) but Bax was up-regulated (augmented) with DF/VC combination in all seven cancer cell lines, indicating induction of apoptosis.
Table 1. Combination of DF and VC on cell viability of various cancer cells.

\begin{tabular}{|c|c|}
\hline Cancer Cell Lines & $\begin{array}{c}\frac{\text { Cell Viability (\% of }}{\text { Control) at 24 h }} \\
\text { DF } \begin{array}{c}300 \mu \mathrm{g} / \mathrm{ml})+\mathrm{VC} \\
\mu \mathrm{M})\end{array}\end{array}$ \\
\hline MDA-MB231 (Breast Ca) & $<5 \%(>95 \% \downarrow)^{*}$ \\
\hline A549 (Lung Ca) & $30 \%(70 \% \downarrow)$ \\
\hline AGS (Stomach Ca) & $<5 \%(>95 \% \downarrow)$ \\
\hline Caco-2 (Colon Ca) & $<10 \%(>90 \% \downarrow)$ \\
\hline PC-3 (Prostate Ca) & $<5 \%(>95 \% \downarrow)$ \\
\hline T24 (Bladder Ca) & $<10 \%(>90 \% \downarrow)$ \\
\hline ACHN (Kidney Ca) & $10 \%(90 \% \downarrow)$ \\
\hline
\end{tabular}

*Values in parentheses are the $\%$ of cell viability reduction relative to control (100\%). DF: D-fraction; VC: vitamin C; Ca: cancer.

apoptotic regulator [16], the down-regulation of bcl-2 concomitant with the up-regulation of Bax rather suggests induction of apoptosis. Thus, it is plausible that the drastically reduced cell viability with $\mathrm{DF} / \mathrm{VC}$ combination is more likely attributed to apoptotic cell death.

\section{Discussion}

To help find the way to improve the poor efficacy of chemotherapy on various human cancers, we investigated if a variety of chemotherapeutic drugs could be potentiated with bioactive DF extracted from maitake mush- 
room. As DF has been shown to have antitumor activity with few side effects [6,7], it appeared to be an appropriate agent to be used in our combination study (with various drugs).

Several common human cancers, such as breast, lung, stomach, colon, and urologic (prostate, bladder, and kidney) cancers, were employed and studied. First of all, a dose-dependent study showed the drug concentrationdependent cell viability reduction in a cancer-specific manner (Figures 1(a)-(e)). As those viability reductions (relative to respective controls), except for T24 and ACHN cells (Figures 1(f) and (g)), were confirmed to be statistically significant $(p<0.05)$, drugs tested may have the certain inhibitory or negative effects on cell viability of these cancer cells.

Whether DF would further enhance or potentiate the efficacy of those drugs was then examined. We found that all drugs tested were somewhat potentiated with DF, ranging from the marginal $(7 \%)$ to highly significant (43\%) cell viability reductions (compared to drugs alone). As summarized in Table 2, ACHN cells show the most significant improvement in the cell viability reduction with 5FU/DF combination; from $100 \%$ cell viability with $5 \mathrm{FU}$ alone to $57 \%$ cell viability with $5 \mathrm{FU} / \mathrm{DF}$ combination-i.e. a " $43 \%$ " improved reduction in cell viability. In contrast, A549 cells show the least improvement in such a reduction; from $91 \%$ cell viability with CPL alone to $84 \%$ with $\mathrm{CPL} / \mathrm{DF}$ combination-i.e. only a $7 \%$ difference in the cell viability reduction. Overall, five out of seven cancer cell lines (>70\%), ACHN, T24, PC-3, Caco-2, and AGS cells, show statistically the significant improvement in the cell viability reduction with combinations of specific drugs and DF (compared to individual drug alone). It thus appears that DF could help improve the efficacy of many drugs significantly. However, as such an improvement somewhat varies with cancer types, it will be crucial to explore how different drug/DF combinations would actually work or to better understand their underlying mechanisms. Such study is currently underway in our laboratory.

Additionally, as a unique approach, we examined if combination of DF $(300 \mu \mathrm{g} / \mathrm{ml})$ and VC $(200 \mu \mathrm{M})$ might also have some anticancer effects on those cancer cells. Remarkably, such DF/VC combination was capable of inducing a drastic $\geq 90 \%$ cell viability reduction in six cancer cell lines except for a $\sim 70 \%$ viability reduction in one cancer cell line (Table 1). To gain an insight into how such a profound viability reduction is induced by $\mathrm{DF} / \mathrm{VC}$ combination, possible induction of apoptosis was examined. We found that $\mathrm{DF} / \mathrm{VC}$ combination led to the down-regulation of anti-apoptotic bcl-2 concomitant with the up-regulation of pro-apoptotic Bax (Figure 2), indicating induction of apoptosis [16]. Therefore, the cell
Table 2. Improved cell viability reductions with combinations of drugs and DF.

\begin{tabular}{cc}
\hline Cancer Cell Lines & $\begin{array}{c}\text { Maximum Difference (\%) in Cell Viability } \\
\text { Between Drug alone and Drug/DF Combination }\end{array}$ \\
\hline MDA-MB231 & $\begin{array}{r}9 \% \text { (Cell viability: } 32 \% \text { with PTX vs } 23 \% \\
\text { with PTX + DF) }\end{array}$ \\
A549 & $7 \%(91 \%$ with CPL vs $84 \%$ with CPL + DF) \\
AGS & $18 \%(78 \%$ with 5FU vs $60 \%$ with 5FU + DF) \\
Caco- 2 & $37 \%(87 \%$ with $5 \mathrm{FU}$ vs $50 \%$ with $5 \mathrm{FU}+\mathrm{DF})$ \\
PC-3 & $20 \%(75 \%$ with PTX vs $55 \%$ with PTX + DF) \\
T24 & $35 \%(93 \%$ with CPL vs $58 \%$ with CPL + DF) \\
ACHN & $43 \%(100 \%$ with 5FU vs $57 \%$ with 5FU + DF) \\
\hline
\end{tabular}

DF: D-fraction; PTX: paclitaxel; CPL: cisplatin; 5FU: 5-fluorouracil; vs: versus.

viability reduction induced by $\mathrm{DF} / \mathrm{VC}$ combination is presumably attributed to apoptotic cell death.

Nevertheless, it is rather critical to elucidate the cytotoxic mechanism of $\mathrm{DF} / \mathrm{VC}$ combination, although our separate study indicates a possible involvement/role of oxidative stress. More studies are required for further confirmation.

Taken together, DF/VC combination appears to be superior to any drugs alone or any combinations of drugs and DF tested, and may ultimately induce apoptosis in these cancer cells.

\section{Conclusion}

The present study suggests that D-fraction may have a great potential as an adjuvant agent that can be combined with certain chemotherapeutic drugs or with vitamin $\mathrm{C}$ for the safer and more effective therapeutic modalities for various human malignancies. Further studies are thus warranted.

\section{Acknowledgements}

We thank Mr. Mike Shirota (Mushroom Wisdom, Inc.) for a generous gift of D-fraction and his devoted support.

\section{REFERENCES}

[1] World Health Organization, "Cancer Fact Sheet," 2011. http://www.who.int/mediacentre/factsheets/fs297/en/

[2] A. K. Maiti, "Genetic Determinants of Oxidative StressMediated Sensitization of Drug-Resistant Cancer Cells," International Journal of Cancer, Vol. 130, No. 1, 2012, pp. 1-9. doi:10.1002/ijc.26306

[3] R. J. Motzer and P. Russo, "Systemic Therapy for Renal Cell Carcinoma," Journal of Urology, Vol. 163, No. 2, 2000, pp. 408-417. doi:10.1016/S0022-5347(05)67889-5

[4] M. Fung-Kee-Fung, T. Oliver, L. Elit, A. Oza, H. W. 
Hirte and P. Bryson, "Optimal Chemotherapy Treatment for Women with Recurrent Ovarian Cancer," Current Oncology, Vol. 14, No. 5, 2007, pp. 195-208. doi: $10.3747 /$ co.2007.148

[5] T. Mizuno and C. Zhuang, "Maitake, Grifola frondosa: Pharmacological Effects," Food Reviews International, Vol. 11, No. 1, 1995, pp. 135-149. doi: $10.1080 / 87559129509541024$

[6] K. Adachi, H. Nanba and H. Kuroda, "Potentiation of Host-Mediated Antitumor Activity in Mice by $\beta$-Glucan Obtained from Grifola frondosa (Maitake)," Chemical and Pharmaceutical Bulletin (Tokyo), Vol. 35, No. 1, 1987, pp. 262-270. doi:10.1248/cpb.35.262

[7] I. Hishida, H. Nanba and H. Kuroda, "Antitumor Activity Exhibited by Orally Administered Extract from Fruit Body of Grifola frondosa (Maitake)," Chemical and Pharmaceutical Bulletin (Tokyo), Vol. 36, No. 5, 1988, pp. 1819-1827. doi:10.1248/cpb.36.1819

[8] C. Q. Gu, J. W. Li and F. H. Chao, "Inhibition of Hepatitis B Virus by D-Fraction from Grifola frondosa: Synergistic Effect of Combination with Interferon- $\alpha$ in HepG2 2.2.15," Antiviral Research, Vol. 72, No. 2, 2006, pp. 162-165. doi:10.1016/j.antiviral.2006.05.011

[9] National Cancer Institute, "Developmental Therapeutics Program: In-Vitro Anti-HIV Drug Screening Results," National Science Council F195001, Washington DC, 1992.

[10] Maitake Products, Inc., "D-Fraction Obtained IND for Clinical Study," Corporate Publication, Paramus, 1998.

[11] S. Glauco, F. Jano, G. Paolo and S. Konno, "Safety of Maitake D-Fraction in Healthy Subjects: Assessment of Common Hematologic Parameters," Alternative and Com- plementary Therapies, Vol. 10, No. 4, 2004, pp. 228-230. doi:10.1089/1076280041580341

[12] F. Morishige, "The Role of Vitamin C in Tumor Therapy (Human)," In: F. I. Meyskens Jr. and K. N. Parasad, Eds., Vitamins and Cancer: Human Cancer Prevention by Vitamins and Micronutrients, Humana Press, Clifton, 1986, pp. 399-427.

[13] J. A. Mordente, S. Konno, Y. Chen, J. M. Wu, H. Tazaki and C. Mallouh, "The Effects of Brefeldin A (BFA) on Cell Cycle Progression Involving the Modulation of the Retinoblastoma Protein (pRB) in PC-3 Prostate Cancer Cells," Journal of Urology, Vol. 159, No. 1, 1998, pp. 275-279. doi:10.1016/S0022-5347(01)64081-3

[14] M. F. Ullah, S. H. Bhat, E. Hussain, F. Abu-Duhier, A. Ahmad and S. M. Hadi, "Ascorbic Acid in Cancer Chemoprevention: Translational Perspectives and Efficacy," Current Drug Targets, Vol. 13, No. 14, 2012, pp. 17571771. doi:10.2174/138945012804545669

[15] Q. Chen, M. G. Espey, M. C. Krishna, J. B. Mitchell, C. P. Corpe, G. R. Buettner, E. Shacter and M. Levine, "Pharmacologic Ascorbic Acid Concentrations Selectively Kill Cancer Cells: Action as a Pro-Drug to Deliver Hydrogen Peroxide to Tissues," Proceedings of the National Academy of Sciences of the United States of America, Vol. 102, No. 38, 2005, pp. 13604-13609. doi:10.1073/pnas.0506390102

[16] K. W. Yip and J. C. Reed, "Bcl-2 Family Proteins and Cancer," Oncogene, Vol. 27, No. 50, 2008, pp. 63986406. doi:10.1038/onc.2008.307 